\title{
RECENT INTERNATIONAL DEVELOPMENTS IN THE EVALUATION FRAMEWORK REGARDING ITS INTENDED USES. THE CASE OF EU COHESION POLICY APPROACH TOWARDS THE EVALUATION OF PUBLIC INTERVENTIONS
}

\author{
Mihaela IORGULESCU-AIOANEI, Post-doctoral researcher and evaluation \\ practitioner \\ National University of Political Science and Public Administration \\ Bucharest/Romania
}

\begin{abstract}
The article starts from a comparative view of the evaluation strategies used among relevant global organizations, that streamline the general approach towards the evaluation practice. The analysis is focused on the way in which the current provisions emphasize different ways of evaluation utilization. Then, the analysis zooms in on to the developments of the EU Cohesion Policy evaluation framework in the period 2007 - 2027 towards a more effective process. The article is developed based on the following two key concepts: evidence-based policy and evaluation use. Both concepts emerged from the research efforts that have been developed since the second half of the nineteenth century. Looking at the subject from this perspective, the evaluation of public programmes and policies becomes an instrument for evidence-based policy. Together with the expansion in using evidence-based policy approach from the last two decades, the evaluation practice should have gained more importance in the policymaking cycle. Nevertheless, most of the available data shows that the results of the evaluation process are used in general to a small extent compared with its potential of generating change at the level of policy, programme, project or in
\end{abstract}


terms of organizational culture. In this respect, the aim of the analysis is to answer two key questions: Is the utilization phase sufficiently explicit within the evaluation frameworks developed by international organizations? and Are there other implicit factors that have to be activated/mobilized in the evaluation process so as to increase the role of the evaluation in the policy cycle? The core rationale of putting the focus of the article on this subject is given by the fact that this practice involves engaging considerable financial, human and time resources and when an evaluation does not produce the expected effects it becomes a waste of resources.

\section{Keywords}

Evaluation; evaluation utilization; evaluation policy; evidence-based policy.

\section{INTRODUCTION}

\subsection{Rationale of the analysis approach}

The analysis of the recent developments in regards with the evaluation policies of international organizations provides a comprehensive image on the level of the progress made in the past decade regarding the evaluation practice, its purposes and thus, its acknowledged potential in enhancing the effectiveness and impact of the addressed interventions in the socio-economic area. In this context, the analysis highlights important findings on the extent to which the utilization phase of the evaluation cycle is explicitly addressed, well-grounded and easy to be made subject of operationalization. Moreover, the selected international organisms for this analysis, UNDP, UNICEF, WB and EU, are setting the evaluation guidelines at global level and the practice in the field. They promote certain types of intervention models: based on needs analysis, based on evidence, tested at pilot level, evaluated through several processes (project evaluation, programme evaluations, sector evaluation multi-country evaluation and other).

Zooming in on the developments of the EU Cohesion Policy evaluation framework in the period 2007 - 2027, the paper allows us to analyse the 
prospects of the institutionalization of evaluation in Romania, as a key instrument for informing the policy making process. In this respect, it is important to mention that the EU Cohesion Policy has been the engine of the development of the evaluation practice at national level. Even if there were some efforts put in developing the evaluation framework outside the System of Structural Instruments, the Partnership Agreement (in the previous financial cycle, the National Strategic reference framework) remains the core of the evaluation culture in Romania.

\subsection{Paper structure}

The first analysis question is going to be addressed within the section related to the changes and progress made at the level of evaluation policies within international organizations. This part of the article aims at identifying the extent to which the utilization phase of the evaluation is sufficiently defined, described, operationalized and monitored according to the addressed evaluation frameworks.

The second analysis questions will be addressed within the $4^{\text {th }}$ section of this paper which aims to highlight the extent to which the developments in the framework of the Cohesion Policy evaluation manages to bring in front the potential of the evaluation process in generating knowledge transfers and informing the policy making process. Further, based on the experience of Romania in the previous and current financial cycles, the analysis aims at identifying the implicit factors that can led to an enhancement in the evaluation use and the extent to which the process can become more sensitive to them.

\section{BRIEF CONCEPTUAL CLARIFICATION}

The developments in the theory of evaluation uses and utilization highlight two distinct types of utilization: the utilization which occurs during the evaluation process and the utilization of the evaluation findings. As a traditional way of 
understanding the evaluation use, the instrumental type of utilization refers to "direct transfer of evaluation's results into actions" (Vedung 2008, 269). This implies that the evidence and findings of the evaluative process lead directly to changes at the level of current programmes/interventions or developments for future programmes. In this regard, the evalution is seen as an instrument that can support the policy making process by proving the necessary evidence for decision makers. According to Cousins, the instrumental utilization can be seen as an "support [instrument] for distinct decisions" (Cousins and Leithwood 1986, 344).

Further, in the past decade, this approach has been developed more in the direction of knowledge transfers facilitated by both the evaluation process and its findings. This perspective begun with the classification of Pelz, that introduced, besides the instrumental use of evaluation, the concepts of conceptual utilization and symbolic utilization (Pelz 1978, 348). The conceptual utilization refers to the changes that can be observed at the level of the key stakeholders regarding the level of their understanding towards way in which an intervention is functions according to its plan. The symbolic type of utilization refers to the situations where the results of the evaluation are used to legitimate decisions that were prior made. In this respect, the evaluation does not generate changes at the level of the evaluation object or future similar interventions, but proofs the successful effects of an already made action or decision. In this regard we can refer to the accountability purpose of the evaluation.

Nevertheless, these concepts have been better defined in recent years, when the importance of the evalution as a learning process benefiting more stakeholders become widely accepted. Weiss calls this type of evaluation use "enlightenment" and Mark and Henry describes it as a "gradual sedimentation of theories, concepts and perspectives" $(2004,36)$. Therefore, the instrumental utilization of the evaluation may occur after the finalization of an evaluation and its effects on the addressed intervention may be tracible, if there is a wellestablished procedure that regulates this type of transfers or changes. Whereas, the conceptual approach refers to changes that manifest themselves at the cognitive level of those that get in touch with the evaluation results (Aioanei 
2016, 37). Nevertheless, it is important to mention that this type of changes may lead and should lead to changes at the level of intervention, in the policymaking process, but its effects may occur in time and are more difficult to be observed or directly linked with the evaluation process. Therefore, the instrumental evaluation use may be consecutive to the conceptual one. In this regard, the conceptual type of utilization can be assimilated to the organizational learning concept.

Further than that, the specific literature tackles the factors that can lead to an increase in the evalution utilization, both at an instrumental and organizational levels. The most important factors emphasized in recent studies are: context, evaluation quality, trust in the evaluation findings and conclusions, interest of the key stakeholders in the evaluation findings and the institutional arrangements towards the utilization phase of the evaluation cycle.

Moreover, as will be presented further, the participatory approach within the framework of the evaluation practice has gained significant importance in last decade. The hypothesis on which this approach is based is that the engagement of key stakeholders in the evaluation process leads to a common understanding of the process, trust in and validation of the findings and the acknowledgement of the utility of evaluation recommendations. Therefore, this approach should contribute to strengthening the role of the evaluation as a policy improvement mechanism. As Patton underlies, "the way in which the evaluation is carried out, starting from the elaboration of its design, will determine its real and final impact" (Patton 2008, 20).

\section{CHANGES IN THE EVALUATION POLICES OF INTERNATIONAL ORGANIZATIONS AND ORGANISMS}

\subsection{United Nations Development Programme's evaluation policy}

The evaluation policy document from 2006 defines the evaluation as a "is judgment made of the relevance, appropriateness, effectiveness, efficiency, impact and sustainability of development efforts, based on agreed criteria and benchmarks among key partners and stakeholders. It involves a rigorous, 
systematic and objective process in the design, analysis and interpretation of information to answer specific questions" (UNDP 2006, 4). The main purpose of the evaluation under this framework is to support accountability of UNDP's work. As stated in the first paragraph of the policy document, the purpose of the evaluation is to "organizational learning and effective management for results, and to support accountability" (UNDP 2006, 1). Nevertheless, through the policy document, the accountability aim is emphasized and the aim of facilitating the learning process refers to the wider community of stakeholders and not particularly to the primary intended users, that should be the programming units.

One of UNDP principles, manage for results is supported by the evaluation process due to the fact that it generates evidence on the "the extent to which UNDP's processes, products and services contribute effectively to development results affecting people's lives" (UNDP 2006, 3).

In terms of types of evaluations, as presented in the below figure, UNDP conducts 3 types of evaluations: a) strategic evaluations conducted by the evaluation office and focused on area of intervention; b) programme evaluations conducted by the evaluation office and focused on global, regional and southsouth programmes and c) descentralized evaluations conducted by country offices and focused on outcomes and country programmes. 


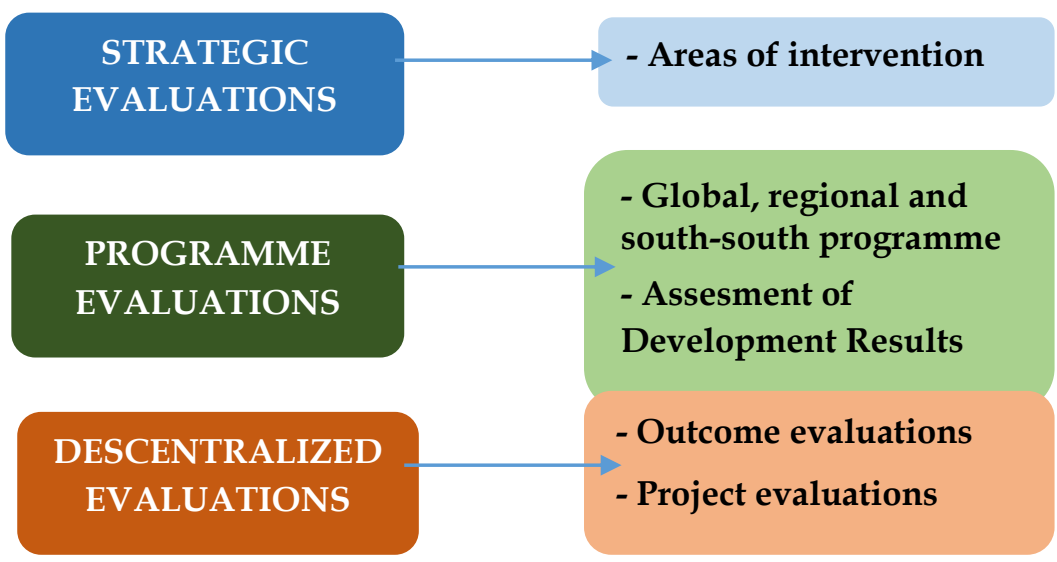

Figure no. 1. Types of evaluations according to the UNDP framework of 2006 Source: information processed from UNDP evaluation framework 2006

In regards with the utilization of the evaluation, the document from 2006 puts a strong emphasis on the evaluation use, by explicitly addressing the utilization process. The document includes a dedicated chapter, use of evaluation findings and recommendations (UNDP 2019, 11). The chapter establishes that for every evaluation there should be developed a plan for the implementation of the recommendation. The progress made in this direction should be periodically assessed by the Evaluation Office. Moreover, this should also be a subject of assessment in the audit process. This last provision, took the evaluation more towards the traditional meaning of the process and less to a activity designed for learning effects. The policy also explicitly sets up the actions that need to be taken into account for wider use and dissemination of findings, namely: online publication of the evaluation report, translation in 3 working languages of UNDP and in the local language. In this stage the learning purpose of the evaluation becomes more visible, due to the fact that the policy document states that stakeholders should have access to the evaluation findings for learning purposes. 
The revised policy brings in front the institutional structure behind the evaluation process, but also it covers the use of the evaluation fundings. Even if this phase of the evaluation cycle does not receive a distinct chapter, but a subsection of the policy document, under chapter IV. Evaluation procedures and quality assurance, the process is better defined. In this regard, the policy provisions that the addressed parties from UNDP/intended users, management of UNDP, United Nations Capital Development fund (UNCDF) and United Nations Volunteers (UNV) should prepare a "management response" for the conducted evaluations (UNDP 2019, 5). Therefore, the responsible bodies should prepare a planning document for each evaluation that sets out the responsible, the timeframe and necessary budget for addressing each recommendation from the study. These plans should be discussed and agreed with key stakeholders before deciding on their final version. Moreover, the implementation status of the management response has to be assessed and presented annually to Executive Board. The implementation of the action plans is then followed-up by the Independent Evaluation Office, who cand conduct on-the-spot visits in this regard.

This is a very good example of how the evaluation utilization phase should be explicitly included in the evaluation framework as to ensure that the primary intended users take into account the outputs of the evaluation process, this being also part of the accountability principle.

Another important issue addressed within the evaluation policy, that focuses on increasing the use

of the evaluation process is the performance measurement system. The document explicitly points out that the extent to which UNDP bodies are able to implement a more effective system of indicators, that capture in a comprehensive manner the outputs and outcomes to be achieved by the planned interventions influence in a significant manner the quality of the evaluation studies conducted. The lack of credible, valid administrative and monitoring data (and in correspondence with the logic of intervention in the case of monitoring data) is one of the most often bottlenecks encountered by the experts in the evaluation process. The fact that the new policy emphasizes this aspect leads to the idea that indeed the past experience of the evaluation process let to 
the transformation of a generalized finding into a lesson learned and facilitated a learning process at the level of the programming units within UNDP. The document explicitly says that "the quality and utility of the evaluations are greatly enhanced project and programme frameworks which [...] establish a theory of change articulating how activities and outputs are expected to lead to desired outcomes and results" (UNDP 2019,5).

\subsection{UNICEF's evaluation framework}

As stated in the 2008 evaluation policy of UNICEF, the purpose of the document was to provide the guidelines of the evaluation process that will ensure "UNICEF has timely, strategically focused and objective information on the performance of its policies, programmes and initiatives to produce better results for children and women" (UNICEF 2008). The document explicitly states that the evaluation process should pe planned as to ensure that the findings conclusions and recommendations can be included in the decision-making processes. The 2008 evaluation framework of UNICEF focuses on the relevance, effectiveness and efficiency criteria and its subjects are UNICEF's policies, programmes and initiatives. Nevertheless, the focus on the 3 aforementioned criteria puts the evaluation phase policy making process at the operational level, with aims at assessing the extent to which the planned and implemented interventions lead to the expected result for children and women.

Moreover, the evaluation policy establishes that the evaluation process must be taking into account from the early stage of programming and necessary resources must be allocated for this purpose. 


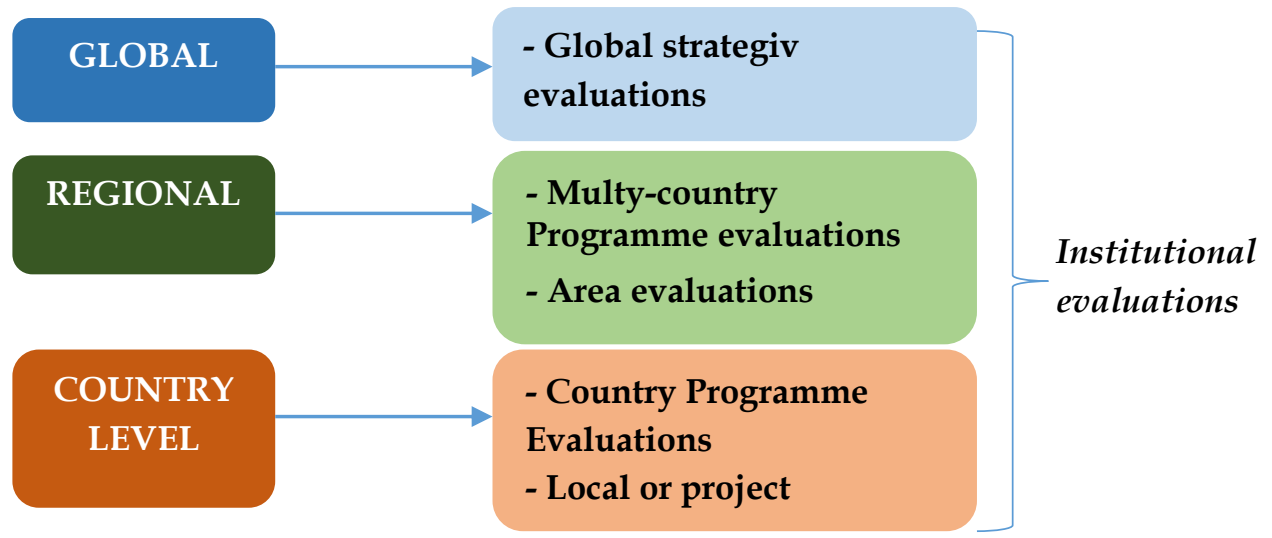

Figure no. 2. Evaluation levels according to 2008 UNICEF evaluation policy Source: information processed from UNICEF evaluation policy 2008

The document briefly addresses the utilization of evaluation results by stating that the findings and recommendations should be public and the finalization of each evaluation should be followed-up by an action plan for the implementation of the recommendation (UNICEF 2008, 8). No further details regarding this process are established at this level.

In regards to the measures proposed for increasing the role of the evaluation system in the policy-making cycle, UNICEF states that the monitoring system should be improved as to be able to better inform the evaluation process and thus, to increase the reliability of evaluation findings and conclusions. This is a key element that facilitates the instrumental utilization of the evaluation studies. The 2013 revised evaluation policy of UNICEF, includes a novelty element the organization of the evaluation function. Therefore, the policy document emphasizes the institutional and normative design of the evaluation function. Also, the revision of the evaluation framework was grounded in the lessons learned from the implementation of previous policy, that showed a need for better plan, in terms of timing, the evalution process as to be able to contribute more to the policy-making process (including the development country programmes) and better budgeting the process (UNICEF 2013). The document 
also states that there is a need for more interim or formative evaluation that can contribute to the progress in the implementation of interventions that are in progress. The focus on assessing the extent to which UNICEF manages to achieve the planned results remains one of the core elements of the policy. Another novelty of the evaluation framework is the $4^{\text {th }}$ evaluation criteria added the 3 already existing in the 2008 document (relevance, effectiveness and efficiency), the sustainability of implemented intervention. As a last general point referring to the need of a revised policy, as perceived at that moment in time, insufficient evaluation capacity was identified at the level of UNICEF Country Offices. Therefore, the document also addresses this issue.

The policy document states that the evaluation process aims "to help UNICEF continually to improve its performance and results" (UNICEF 2013, 4). In this respect, a detailed system regarding the follow-up on the implementation of evaluation recommendation is set up. First of all, the management response document should be developed with the participation of key stakeholders and each measure proposed should pe agreed up with responsible entities. For the recommendation that are not included in the plan there should be provided a pertinent justification. Second of all, actions regarding the changes at the level of programs that have been evaluation may be taken once the management response is approved (including putting the implementation on hold). And finally, the plan has to be uploaded in the tracking system and filled with it status of implementation each 3 months.

Regarding the revised evaluation policy from 2019 (UNICEF 2018), the new document emphasizes the importance of developing the capacity of UNICEF to design interventions based on well informed theories of change and to provide a facilitating context for the learning process that should take place when an evaluation is conducted. Another evaluation criterion is explicitly included in the evaluation framework, namely the impact of assessed interventions. The change of perspective from the focus put on accountability to learning and support for decision-making purposes is very well articulated in the document. Also, a distinct chapter is dedicated to ways of enhancing the use of evaluation. In this regard, the policy aims at improving, on one hand, the planning of evaluation in terms of timing, and on the other, the design of the evaluations in 
respect to clarity of objective and appropriate evaluation question that cand effectively focus the evaluative research.

Moreover, the knowledge management component of the evaluation function of UNICEF is better captured and addressed. The document emphasizes that this is "a key aspect of institutional learning" (UNICEF 2018, 18) and that the Evaluation Office should ensure the information generated by the evaluations, in a synthetized form, is available to all UN bodies.

As it can be observed in the above analysis on the extent to which the evaluation policies address the utilization phase of the evaluation cycle, UNICEF has improved its evaluation policy since 2008, by allocating more resources for this process (2008 version), by making it more operational regarding the implementation of recommendations (2013 version), by clarifying specific issues related to the enhancement of evaluation use (2013 and 2018 versions) and). Maybe, the most important progress made refers to the emphasis put on the correlation of the evaluation process with the programming one, that aims to increase the extent to which the findings and conclusions of the evaluation studies can lead to actual changes in future programmes and interventions.

At UNICEF level there we can observe a greater focus on restructuring the policy-making process, such that the evaluation process gains an increasingly important role.

\subsection{World Bank's evaluation policy}

The World Bank Group Evaluation Principles, document issued in 2019, states that that the purpose of a common policy is to "strengthen accountability and learning through evaluation" (WB 2019). The document is based on WB practice in the evalution field and on the existing international standards and principles and it comes in response to the recommendations of the External review of the IEG, from 2015, that identified the need for a common evaluation policy that comprises the core principles of the evaluation practice within WB. The document is the first normative act setting up the common evaluation principles. 
The guide acknowledges that the evaluation is very importance in the process of evidence-based policy making, due to its capacity to respond, based on the assessment of current or past intervention, to the following question: What works and what doesn't work? The development of the evaluation framework within the WB is based on its very focused approach, in the area of programme management, on continuously improving interventions based on evidence. The policy document sets clearly the two purposes of the evaluation practice within $\mathrm{WB}$, namely accountability and learning, giving both the same level of importance. The knowledge management system is directly linked with the evaluation process and its potential impact on the assessed and future similar intervention. In this respect, the WB bodies should build upon the advantage of evaluation to rapidly provide evidence of the effectiveness of a programme and in this way to support its improvement.

Moreover, IEG has articulated very well the principles for enhancing the evaluation use. First of all, the document emphasizes that the evaluation utilization is directly linked with the compliance of two principles, that have to be met simultaneously, its relevance and its timeliness. Second of all, the document emphasizes the importance of engaging the stakeholders from the early stage of the evaluation in the process and explicitly presented, the IEG adopts a utilization-focused perspective throughout the entire evaluative process, from the planning stage to the follow-up on the implementation of evaluation recommendations. 


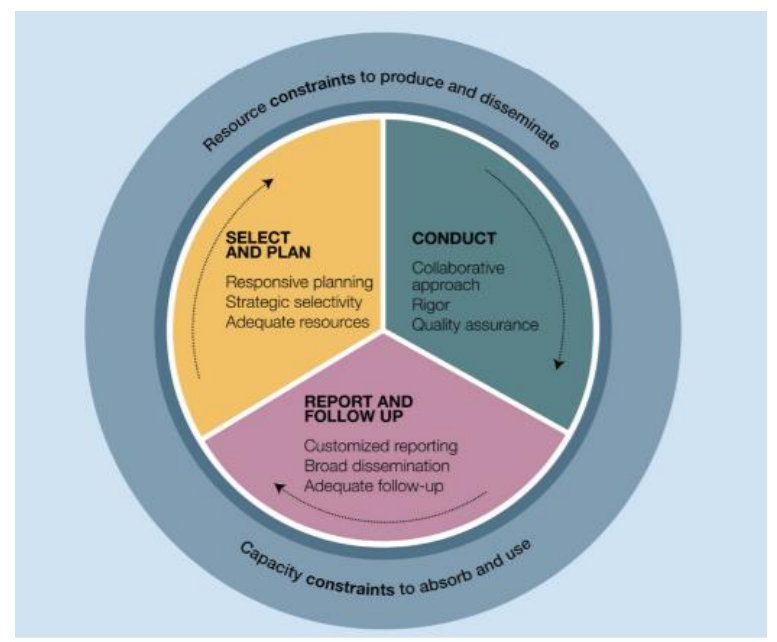

Figure no.3 Evaluation use approach within World Bank Source: The World bank Group Evaluation Principles, 2019

Among the principle of the utilization-focused approach stated in the document, the most important are: engaging the stakeholders and key potential users of the evaluation throughout the whole process and in this way ensuring the fact that the evaluation responds to their informational needs and that the learning process is facilitated, further, allocating resources for the evaluation process in accordance with its potential uses and at the end of the process, developing follow-up plans on the implementation of relevant recommendations (including monitoring procedures for this process).

In 2020, the WB issued the Management Action Record (MAR) report (IEG 2020), which has the purpose of tracking the implementation of the evaluation recommendations and enhancing the process, the "enhance of the evaluation use". The document acknowledges the low level of involvement of senior management and Board members in this process and the slow progress registered at the level of WB in this regard.

The document emphasizes the need of more strategical recommendations and a more effective process on the achievement of their intended outcomes. In this respect, the revised RAM establishes that the progress on the implementation of 
recommendation must be assessed and reported annually. The document describes in a very operative manner the reform of the system and aims for a more meaningful follow-up process, as the recommendations should be fewer and outcome orientated and the monitoring of their implementation should be focused on the progress regarding the expected outcomes and not on the progress of specific planned activities.

In conclusion, we can say that the policy framework developed by WB in respect to the evaluation practice is very well articulated in terms of setting up the principles linked with evaluation utilization process, both as a learning process happening during the implementation of the evaluation and as instrumental transfer of evaluation findings and conclusions into practice as changes at the level of interventions.

\subsection{European Commission's evaluation framework}

EU has very well-developed approach towards the evaluation practice, which is impeded in the system regulation system. The European Commission's evaluation framework is based on the core document that sets up the normative framework of the policy-making process, Better Regulation Guideline. The EC has issued a revised version of the document in November 2021. The European Commission recognizes the importance of monitoring and evaluation in the European Union's policy and law-making cycle. 


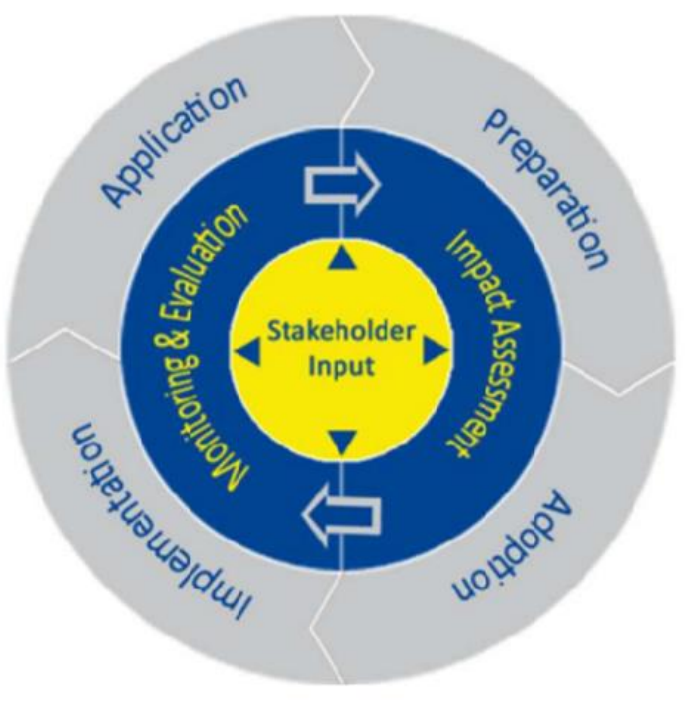

Figure no.4 EU policy and law-making cycle

Source: EC, Better Regulation Guidelines, November 2021 < swd2021_305_en.pdf (europa.eu)>

According to the Organization of Economic Co-operation and Development (OECD) acknowledges that the regulatory system of the EU is one of the most developed ones (EC 2021, 1). The EC reiterates the importance of evidence-based policy and in this regard, emphasizes the role of impact assessments and evaluation. The EC, through the better regulation guidelines, is to provide a framework for improving policies and programmes which is based on learning from previous experiences. In this context, the evaluation has a key role. A very important principle, reiterated in the 2021 guide is "evaluate first", which refers to the practice of evaluating previous experiences before initiating a new legislative initiative or a new intervention.

The evaluation has to take into account the views and perspectives of those affected by the interventions or the new enforced law and those of the key stakeholders. The EC document "Better Regulation: Joining forces to make better laws", from 2021, establishes that the contribution of stakeholders in the improvement of legislative and policy framework of EU should be increased by carefully selecting the issues where the opinion of stakeholders is utmost importance. Several consultations on different areas with the same key actors 
may lead to a reluctance to participate and provide input from their part, due to the fact that this activity requires financial and time resources, becoming a burden. Therefore, the EC proposes to engage stakeholders where their contribution can be the most meaningful. As the practice in the evaluation field shows, in the last years a great attention is given on one hand, to participatory approaches, to engaging key actors in the evaluation field and one the other hand, to the extent to which this practice affects the work, leading to overload them.

Regarding the instrumental use of the evaluation finding, the 2015, 2017 and 2021 toolboxes and guidelines, explicitly describe the follow-up on recommendations phase. The guidelines mention that the commissioners of the evaluation along with the key stakeholders may develop and agree on an action plan, but do not set this phase a mandatory one. Further, the document says that the progress in implementing the plan should be monitored annually and reported in the Annual Activity Reports. For each action should be set the responsible unit that need to implemented it and time coordinates in relation with the finalization of the activity.

As presented above, the EU puts a great importance on the evaluation/impact assessment process in developing better legislation and public interventions. The "evaluate first" principle should ensure that the new development in terms of policy and programmes are evidence based. Nevertheless, even if the instrumental phase of the evaluation utilization is mentioned in every toolbox and guideline, it is not very concrete defined and not mandatory. Due to its specific bureaucratic approach, the learning process and knowledge transfers that happen during the evaluation process is not well captured in the better regulation guidelines. Learning is seen as a process related to accessing the information produces by the evaluation and using it for better design next legislative initiatives or public interventions.

Further, it is important to mention that the analysis of the implementation of the evaluation frameworks presented above was not one of the aims of this article. Even if some reforms or improvements were developed 10 years ago, most important changes in normative terms regarding the utilization of evaluation 
processes and results are very recent and their effects on the ground will become visible in time.

\section{THE CASE OF EU COHESION POLICY APPROACH TOWARDS THE EVALUATION OF PUBLIC INTERVENTIONS}

This chapter shifts the perspective from the policy, strategic level of evaluation to a more operational one in the context of EU policy making and analyses the changes made at the level of Cohesion Policy in regards with the implementation of structural funds and national level and thus, the implementation of the evaluation activity. This section aims to identify the extent to which EC regulations manage to capture the most important aspects of evaluation utilization for the improvement of Partnership Agreement's implementation and results and what can be done more in terms of regulation as to increase its role in this context.

4.1. Changes in the regulations of DG Regio regarding the evaluation activity

In the financial cycle 2007 - 2013, the Council Regulation 1083/2006 establishes within the article 47 (1) that the evaluation practice should aim at improving the "quality, effectiveness and consistency of the assistance from the funds consistency of the assistance from the Funds and the strategy and implementation of operational programmes". According to the regulations, the evaluation was conducted at two levels: a) strategic level, that assesses the contribution of the programme or of several programmes to the EU policies and the national strategies and b) operational level, that aims at evaluating the progress of the programmes against their own objectives. Moreover, based on the timing of the evaluation, the Member Stated (MS) or the Commission, depending on the subject of the evaluation were conducting: a) Ex-ante 
evaluation, prior to the development of a new programme (MSs), b) Interim evaluation, during the implementation period (MSs and EC) and c) ex-post evaluations, after their finalization (EC). In this financial cycle the horizontal themes or more strategic evaluations were under the responsibility of the Commission. The general provisions do not address explicitly the utilization phase of the evaluation cycle. Nevertheless, in Romania, in the period 2007 2013, the Evaluation System of Structural Funds established a well-designed set of procedures in relation with the utilization phase. The procedure B - Stages in the follow-up process is presented below.

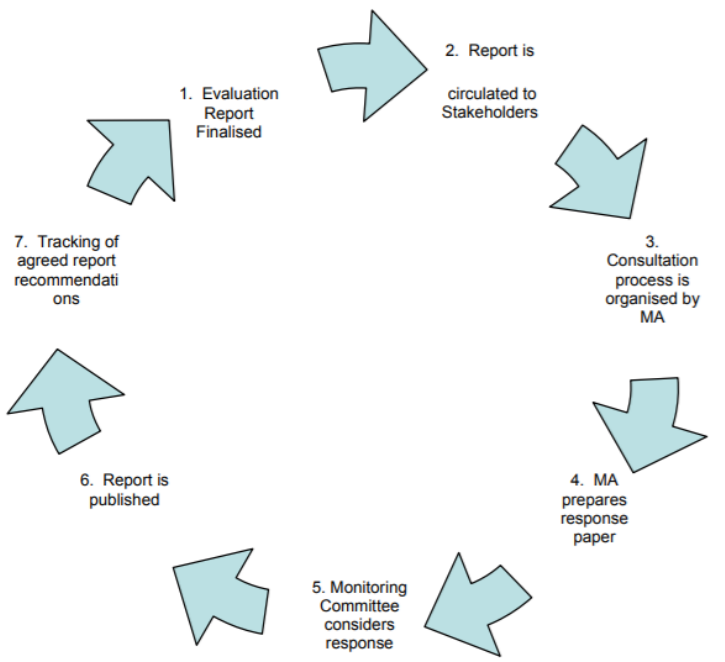

Figure no. 5 Procedure B - Stages in the follow-up process

Source: Procedural Guidance Manual for Evaluation of NSRF Operational Programmes in Romania, 2007-2013 (MFE, 2006, 50)

The action plans for the implementation of recommendation were mandatory for each evaluation conducted. The follow-up documents included each recommendation, the responsible bodies that have to implement it and the timeframe in which the actions taken have to be finalized. Nevertheless, the monitoring process in regards with the action plans progress was inconsistent 
across the Managing Authorities (MAs) of the operational programmes. An analysis of the extent to which the recommendations were implemented by the responsible bodies (Aioanei 2016a, 82-83) showed that, in the cases where the actions plans were developed, which constitute the vast majority of the evaluations conducted, most of the recommendations have been accepted and operationalized. Moreover, in the cases where the follow-up on the action plans has been implemented, a relatively high rate of finalizing the planned activities was registered.

Further, in the period 2014 - 2020, the European Parliament and Council Regulation 1303/2013 brought significant chances for the evaluation framework adopted at the level of MSs. The article 54 (1) from the EU regulation 1303/2013 introduces a new aim for the evaluations conducted at national level, namely assessing the impact of the operation programmes. If the previous period the MSs focused more the evaluation process on the operational level in accordance with the EU regulations, thus on the effectiveness of the programmes, during the implementation phase, in this context, MSs reorientated the evaluation towards more strategic objectives, aiming to assess the impact of the programmes. Once again, the general provisions do not address explicitly the utilization phase of the evaluation cycle.

The available information on the expectations of the management of operational programmes in Romania, highlighted by representatives of the MAs during national and international conferences on the themes of evaluation practice and utilization within the national ${ }^{1}$, show that the high/strategic level of evaluations conducted in the current financial cycle led to the development of more general and wide recommendation for which the operationalization process was more difficult. Also, due to this new approach on the evaluation practice, the findings

1 Such as: National Conference: the evaluation of EISF 2014 - 2020 and perspectives regarding the evaluation in the period 2021 - $2027<$ https://www.evaluarestructurale.ro/web/guest/conferinta-nationala-post-exstins1> or the International Workshop Evaluation - a learning process or a decision-making instrument? How and where does it make a difference? organized within the Evaluation Week 2021, under the framework of GLocal < https://glocalevalweek.org/event/evaluation-learning-processor-decision-making-instrument-how-and-where-does-it-make> 
and conclusions also seemed to be less informative for the programming process.

Even if this has not been the aim of the current paper, this idea presented above needs to be further explored through structured qualitative data collection methods (aiming at gathering information from key stakeholders), in order to be able to grasp in a comprehensive manner the implication of the new regulations on the extent to which the evaluations became more useful for programming units within MAs. Moreover, taken into consideration that many evaluations are still in progress or were recently conducted a comprehensive analysis of the extent to which the recommendations were translated into actual actions could not be developed.

4.2. Looking forward - changes in the evaluation and reporting areas in the financial cycle $2021-2027$

The new regulations regarding the implementation of the Cohesion policy bring several changes to the evaluation framework. The EU Regulation 2021/1060 establish the following evaluation framework for the period $2021-2027$. The figure below also presents the changes made in comparison with the previous evaluation framework. 


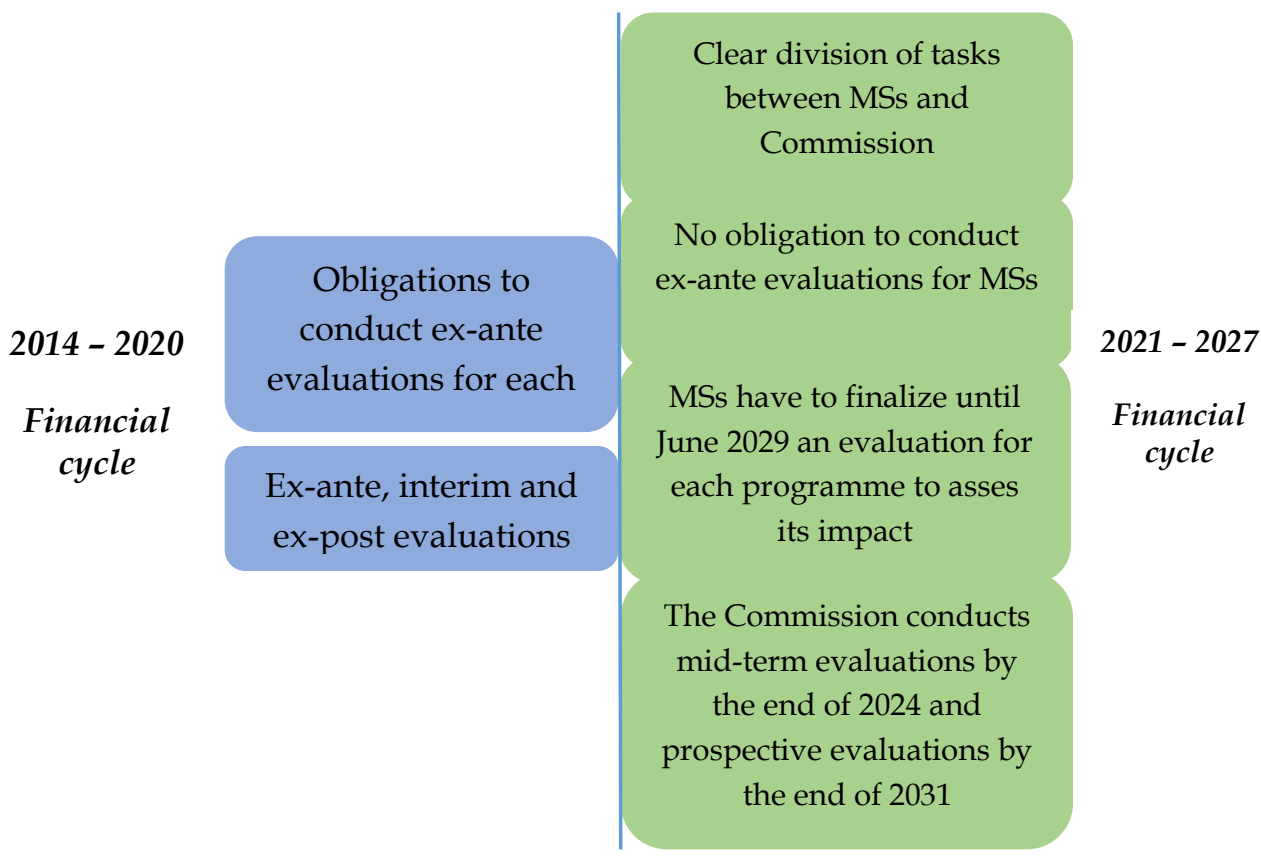

Figure no. 6

Comparison between the evaluation framework in 2014 - 2020 and 2021 - 2027

Source: https://ec.europa.eu/regional_policy/en/2021_2027/\#22

The ex-ante evaluations are not mandatory any more, therefore MSs do not have the obligation to base the operational programmes' design on evidence and findings provided through ex-ante evaluative processes. Nevertheless, the operational programmes must be developed based on the lessons learned from previous experiences. In this case the already conducted evaluations on similar operations will become of utmost importance, due to the fact that they provide evidence on the effectiveness and impact of certain interventions and also because they identify lessons learned and good practice examples. On one hand the changes made in the evaluation framework aim to build up on the evidence and findings of previous evaluations, meaning that they increase the role and value of evaluation studies conducted in the period $2014-2021$, but they limit 
the responsibility of MSs in conducting evaluation. Thus, they lower the involvement of the MSs in the evaluation process. In the care of Romania, where the System of Structural Instrument constitutes the core of the evaluation practice at national level, this may affect the progress in further development of an evaluation culture.

Moreover, the new regulations have also changed the reporting system regarding the achievements of each operational programme, which is directly linked with the evaluation system and its efficacy. The new regulation of the EU in regards with the reporting system established under the Cohesion Policy do not request any more the elaboration of Annual Implementation Reports at the level of Operational Programmes, but only of a Final Performance Report for programmes supported by the ERDF, the ESF+, the Cohesion Fund (EU 2021, 52). The document introduces a new system of real-time reporting, based on the indicator achievement rates/progress. The MS should electronically submit to the EC, every 3 months, for each program data on the financial and physical progress of each programme against the allocated budget and the established indicators framework (Annex VII of REGULATION (EU) 2021/1060). Nevertheless, annual meeting will be held with the EC in order to review the progress programmes. After the annual review is finalized, MS should take actions regarding the issues signaled during the meetings and affecting the progress of the programme and further to inform the EC each 3 months on the process.

In the case of Romania, as proved from several evaluations of the operational programmes the implementation phase and thus the progress in delivering results is usually delayed, therefore, without any qualitative data regarding the progress of the intervention, the available data for evaluations and for timely identifying problems or bottlenecks in the implementation process and will not be sufficient. This is an idea that had also been highlighted during the first conference organized by the Romanian Evaluation Network (RER), in 2021. Therefore, the new approach emphasized less the role of the MSs in the evaluation process and in this way affects the extent to which the evaluation can be perceived as an essential instrument for improving the implementation of the interventions (due to its capacity to provide rapidly, relevant and meaningful 
data on what it works and why in the context of policy making process). To certain extent, the approach also lacks in taking into consideration the national contexts in which is applied.

\section{CONCLUSIONS}

The utilization phase with the evaluation cycle has become more and more addressed in the evaluation policies of international organization. The manner in which this phase has been defined and operationalized in the revised evaluation policies shows that a transformative process took place at the level of these organizations and their evaluations capacity has been increased. Bringing in front aspects as: a) better development of the theories of change, b) improvement of the quality of monitoring systems, and c) better planning the evaluation studies as to be able to timely inform the programming process, leads to the idea that the evaluation process starts to gain more importance in the policy making cycle. Moreover, the conducted analysis of policy documents offers us the possibility to conclude that even if the accountability purpose of the evaluation process remains valid, the learning purpose and the purpose of providing evidence for programing process have gained much more importance in the past few years. This development has been catalyzed by the strengthening of the evidence-based policy concept, this being a momentum for the institutionalization of the evaluation practice as an instrument for policy and programme improvement. Another important improvement of the evaluation framework is the emphasis put on the consultations with stakeholders during the process and in regards with the development of the actions plans for the implementation of the recommendation. This facilitates not only an effective instrumental utilization of the evaluation results, but most important, a learning process, based on experience and knowledge exchange.

Nevertheless, at national level, the sector does not progress in the same pace. As the showed in the justification section of the article, the importance of the evaluation frameworks adopted by international organizations, such as UNDP, UNICEF, WB and EU, stands in the fact that they represent one of the 
development engines of the valuation field and thus, they set guidelines for other organisms from private and public sector. They become points of refence for the benchmarking process. In the particular case of the EU and further, of the evaluation framework within the Cohesion Policy, the latest developments show that a great emphasis is put on the capacity of the evaluation process to gather useful evidence for designing new legislative initiatives and interventions or improving the current ones. Nevertheless, the utilization phase of the evaluation cycle is not very well articulated and this may be caused by the fact that the evaluation is seen as an embedded phase of the programing cycles and its utilization does not have to be explicitly regulated. It important to mention here that the Cohesion Policy regulations for the period 2021 - 2027, bring more responsibilities in regards to the evaluation process to the EC and decreases to a significant extent the MSs involvement. This new approach can lead to a more structured and effective evaluation process, but it may also affect the learning process and organizational capacity development at the level of the operational programmes' management. Further, due to the fact that in the case of Romania, the engine of the development of an evaluation culture has been and still is the European Cohesion Policy, the progress in this regard will be slowed down by the new regulations.

\section{ACKNOWLEDGEMENTS}

This article was elaborated within the Human Capital Operational Program 2014-2020, co-financed by the European Social Fund, under the project POCU/380/6/13/124708 no. 37141/23.05.2019, with the title "ResearcherEntrepreneur on Labor Market in the Fields of Intelligent Specialization (CERTANTREP)", coordinated by the National University of Political Studies and Public Administration. 


\section{REFERENCES}

- Aioanei, Mihaela. 2016. Evaluation as a change instrument. The institutionalization of the evaluation as a mechanism for improving the operational programmes within the System of Structural Instruments. PhD diss. National University of Political Science and Public Administration.

- Aioanei, Mihaela. 2016. "Improving structural interventions through the evaluation process. Case study - The Regional Operational Rrogram of Romania 2007 - 2013". Europolity. vol. 10. no. 2: 33 - 74.

- Alkin, Marvin and Rehat Daillak. 1979. "A Study of Evaluation Utilization. Educational Evaluation and Policy Analysis". vol. 1. No. 4: 41-49.

- Balthazar, Andreas. 2006. "The Influence of Institutional Design on Evaluation Utilization". London: SAGE Publication. vol.12. no. 3: 353-371.

- European Commission. 2021. Better Regulations: Joining forces to make better laws.

https://ec.europa.eu/info/sites/default/files/better_regulation_joining_f orces_to_make_better_laws_en_0.pdf.

- European Commission. $2015 . \quad$ Better Regulation Toolbox. https://ec.europa.eu/info/sites/default/files/better-regulation-toolbox2015_0.pdf.

- European Commission. $2017 . \quad$ Better Regulation Toolbox. https://ec.europa.eu/info/sites/default/files/better-regulationtoolbox.pdf.

- European Commission. 2021. Better Regulation Guidelines. swd2021_305_en.pdf (europa.eu).

- European Union. 2006. Council Regulation 1083/2006 laying down general provisions on the European Regional Development Fund, the European Social Fund and the Cohesion Fund and repealing Regulation (EC) No 1260/1999. https://eur-lex.europa.eu/legalcontent/EN/TXT/PDF/?uri=CELEX:32006R1083\&from=CS.

- IEG. 2020. Management Action Record Reform, IEG's Validation Report. https://ieg.worldbankgroup.org/sites/default/files/Data/Evaluation/file s/marvalidationreform.pdf .

- Mark, Melvin and Gary Henry. 2004. "The Mechanisms and Outcomes of Evaluation Influence." Evaluation. London: SAGE Publishers. vol.10. no. 1: 35-57. 
- Ministry of European Funds, Central Unit of Evaluation. 2006. Procedural Guidance Manual for Evaluation of NSRF Operational Programmes in Romania, 2007-2013.

https://www.evaluarestructurale.ro/documents/20126/55913/Proceduri_generale_en.pdf/aaf01 d7b-ad51-26b2-8c3c-8ad08957fa2f?t=1555924977425.

- Patton, M. Quinn. 2008. Utilization-Focused Evaluation: The New Century Text. SUA: Sage Publications.

- Shulha, M. Lyn și J. Bradely Cousins. "Evaluation Use: Theory, Research and Practice since 1986." Evaluation Practice, 1997. Vol. 18, no. 3: 195 - 208.

- United Nations Child's Fund. 2008. E/ICEF/2008/4 UNICEF Evaluation Framework. https://digitallibrary.un.org/record/615249\#record-filescollapse-header.

- United Nations Child's Fund. 2013. E/ICEF/2013/14 UNICEF Revised Evaluation Policy. https://undocs.org/E/ICEF/2013/14.

- United Nations Child's Fund. Evaluation Office. 2018. Revised evaluation policy of UNICEF.

- United Nations Children's Fund, Evaluation Office. 2019. Revised evaluation policy of UNICEF.

- United Nations Development Programme. 2006. DP/2006/28 The Evaluation Policy of UNDP. Geneva, June 2006.

- United Nations Development Programme. 2019. The Revised UNDP evaluation Policy. New York. September 2019.

- World Bank Group. 2019. Evaluation principles. https://ieg.worldbankgroup.org/sites/default/files/Data/reports/World BankEvaluationPrinciples.pdf. 